Session 3266

\title{
Lessons Learned in Mechanical Engineering Capstone Design Classes
}

\author{
Kendrick Aung \\ Department of Mechanical Engineering \\ Lamar University, Beaumont, Texas 77710
}

\begin{abstract}
For all engineering students, senior capstone design course is a required course for completion of their bachelor degree. With more emphasis on the design contents in engineering curricula, the importance of capstone classes for students cannot be overemphasized. This paper described the author's experiences in conducting capstone classes for the last three years in the Department of Mechanical Engineering at Lamar University. The paper presented difficulties and problems encountered in completing these projects from the viewpoints of both instructor and students. Each project and the problems associated with it were discussed in details. The experiences and lessons learned from these projects are applicable to most capstone design projects and thus, the paper will be beneficial to other instructors teaching capstone design classes.
\end{abstract}

Introduction

Senior capstone design classes represent the penultimate experience for undergraduate students in completing their bachelor degree. These classes require higher learning skills involving analysis and synthesis of knowledge and information to solve a real-world engineering problem. In many engineering curricula, capstone design is the class where students gain experience with the complete design process including defining the problem, generating engineering specifications, developing and evaluating conceptual designs, choosing final design, and conducting engineering analysis on the final design. In some cases, students have the chance to implement and test their design to see whether their application of concept, knowledge, and analysis on their design work out as planned. With more emphasis on the design contents in the engineering curricula, the importance of capstone classes for students cannot be overemphasized.

This paper described the author's experiences in conducting capstone classes for the last three years in the Department of Mechanical Engineering at Lamar University. The paper presented difficulties and problems encountered in completing these projects from the viewpoints of both instructor and students. Each project and the problems associated with it were discussed in details. 


\section{Course Descriptions}

The curricula for the mechanical engineering students at Lamar University require completion of two consecutive semesters of senior design classes: MEEN 4310 Integrated Systems Design and MEEN 4316 Senior Design Project. The first course deals with the design process culminating in the paper design with complete engineering drawings and parts specifications. For the second course, the students actually build and test their designs developed in the first course. Similar two-semester sequence of senior design classes can be found in Michigan Tech $^{1}$ and Georgia Tech $^{2}$.

\section{MEEN 4310 Integrated Systems Design}

This is the first course in the two-semester sequence of the capstone design class. The class is a three credit hour course with two one-hour lectures and one three-hour lab session per week. Typically, senior students graduating in spring semester take this class in the fall semester preceding the spring semester. When they take this class, the students have already completed most of the junior and senior level classes except the electives. The text for the course is The Mechanical Design Process by David Ullman ${ }^{3}$. The text is chosen as it clearly outlines and explains the processes involved in developing an engineering design. In addition, the text covers different phases involved in developing and marketing the product based on the selected design. The chapters on product development are not covered, as the emphasis of the course is to teach the design process. Thus, the text is only followed closely for the first eight chapters so that the students understand the steps involved in coming up with their conceptual designs and selection of the final design.

In the first week of the class, the students are asked to form a team consisting of three to five people and chose the name of the team. Sometimes, a team of two people is allowed depending on the scope of the project. At the same time, the instructor discusses the importance of building schedule for the semester, specifying the tasks to be completed, and identifying the milestones to be achieved during the semester. During the course, the students develop conceptual designs and analysis of two sample projects. These are given in order to provide experiences in applying the concepts covered in the text to the real-world design problems. One design exercise is to design a drive-train system with given space and load requirements from the following choices: gears, belts, and chains. The students are asked to evaluate different choices to come up with the final drive-train system. The other exercise is the design of a heat exchanger for a power plant. The students identify the most appropriate heat exchanger among different types available for the problem. These two exercises help students to gain familiarity with the design process and to apply the knowledge they have learned from the text on the design process.

During the semester, the students also give two progress presentations on their respective project. At the end of the semester, the students complete the project design report and make the final presentation of their paper design. The technical report must include the following sections: design procedures, description of the conceptual designs and their evaluations, the selection of the final design, engineering analysis and calculations of the final design, engineering drawings, 
parts specifications and costs, and the timeline for the next semester. The students are also required to prepare the requisitions for the parts and place the orders for the next semester.

\section{MEEN 4316 Senior Design Project}

This is the second course in the two-semester sequence of capstone design class. The class is a three credit hour course with one one-hour lecture and two three-hour lab sessions each week. From the beginning of the semester, the students start to build their design. The building and testing are the main activities for the students in this semester. Ethics and project management are the only topics discussed during lecture hours. As the semester progresses, the students start testing their design after completing the assembly of their design. They need to solve problems encountered during the assembly and testing before the end of the semester. Every week, the instructor meets with each group of students to discuss the project, to keep track of the progress, and to learn the problems. During the semester, each design group makes two progress presentations followed by the question and answer session. At the end of the semester, the students complete the final report and make the final presentation of their design.

\section{Descriptions of the Projects}

The author has guided 8 design projects during the last three years at Lamar University. Only two projects from these classes were discussed in this paper. The first project involved the design of a laboratory-scale test stand for demonstrating air-conditioning processes using the Senior Design Grant from American Society of Heating, Refrigeration, and Air-conditioning Engineers (ASHRAE). The second project was the design of a paper snowboard for 2004 Energy Challenge competition sponsored by Department of Energy (DOE) and Institute of Paper Science and Technology (IPST).

\section{ASHRAE Project}

This project received one of the senior project grants from ASHRAE. Every year, ASHRAE awarded grants for its senior design grant program ${ }^{4}$. The program is intended to provide engineering and technical schools with funding to build and test HVAC related experiments in senior design classes. ASHRAE awarded up to $\$ 5,000$ for the project to cover the costs of materials, instrumentation and fabrication for the project. The instructor must submit the grant proposal to ASHRAE in early December and ASHRAE made decisions on the proposal in early March. If the grant is awarded, the school will receive the funding in August so that the project can start in the fall semester.

The problem statement of the project was to build and test a test stand for demonstrating thermodynamic process of air-vapor mixtures. Thus, the students did not need to identify the problem statement as it had already been decided for them from the project description. The test stand is to be used as a laboratory experiment in MEEN 3210 Measurements Lab course. As for students, the goal is to design a chamber that takes air through four processes: heating, cooling, humidification, and dehumidification (Fig. 1). Some of the design issues that were considered were noise, manufacturing time, cost, and performance. Noise is the primary factor as the stand is to be used in a lab environment. The cost of the unit is considered as a factor even though 
there is a grant of $\$ 5,000$ from ASHRAE as it is the deciding factor for most of the practical situations. Based on these criteria, the students used the house of quality (HOQ) and the decision matrix to determine the best order of the four processes.

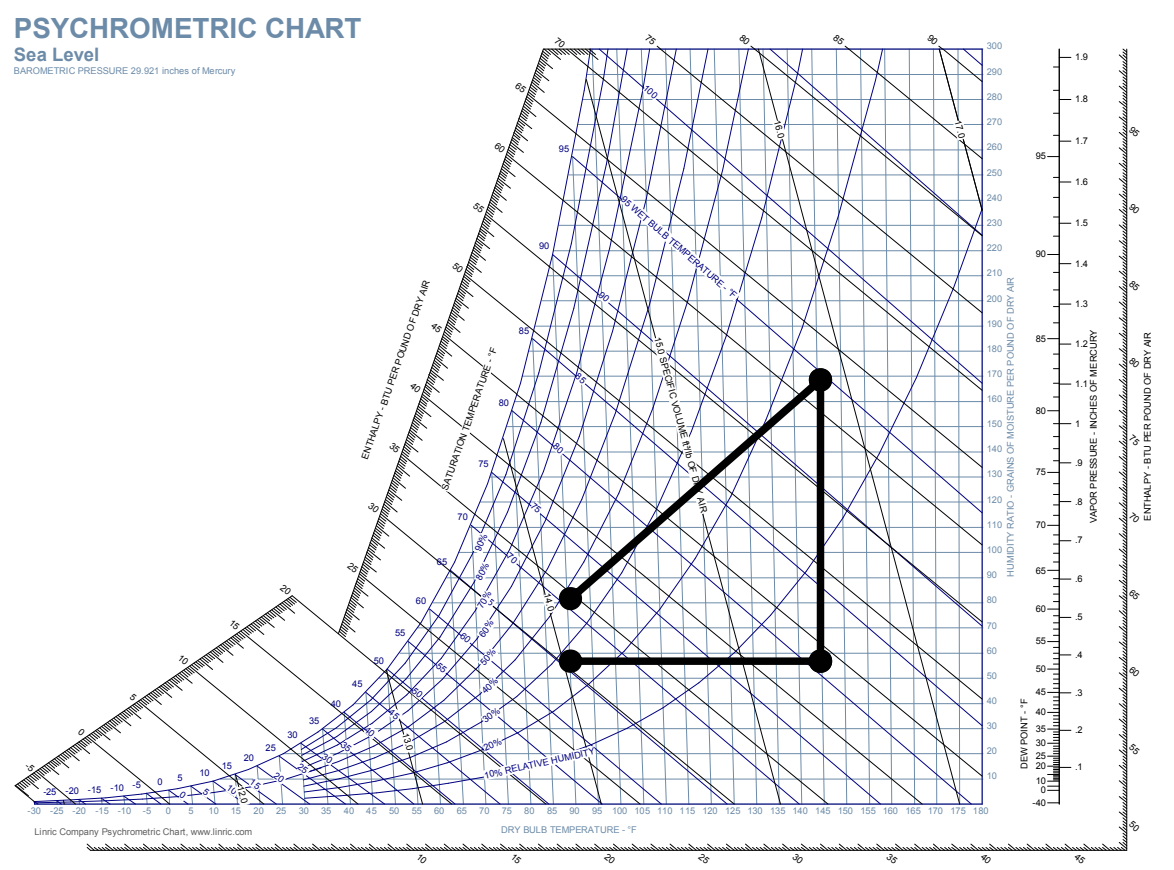

Figure 1 A Schematic of the Psychrometric Processes

The first challenge encountered by the students was to find out where and how to start the project. Here, the guidance of the instructor was critical to the students so that they will be able to identify the controlling/critical parameters for the design. After discussions with the students, it was decided that noise was the controlling factor for the design. The students first found out the acceptable level of noise from the literature. Then, they determined that the flow rate of air was the key factor in deciding the size of the chamber. They used DuPont standards, which are the regulations and recommendations for airflow in many different air conditioning systems, to identify the allowable air velocity in the chamber and the chamber size.

The chamber size was a deciding factor for the subsequent engineering analysis as the space allocation for the chamber was decided by the available space in the lab. Using the acceptable noise level and the chamber size, the students chose the most appropriate blower for the experiment. Once the blower was selected, they conducted engineering analyses of psychrometric processes to determine the conditions of air at different stages of the chamber. Heating was accomplished by an electric heater and humidification by a sprayer. Dehumidification and cooling was achieved by passing the hot and humid air through the evaporator coil of an air-conditioner. In this stage, the students were forced to consider practical issues such as how to connect the blower to the chamber, how to collect the water from the sprayer and how to mount the evaporator coil inside the chamber. 
Once the details of the processes were computed, the students started choosing the instrumentation for the chamber. The instruments chosen were six thermometers (for both dry and wet bulb temperatures at three locations) to measure the temperatures, a hygrometer probe to measure humidity and temperature, and an air velocity meter to measure the air flow rate. At the end of the first semester, the students completed their design and identified the instrumentation to be used.

The next semester, the students started their assembly and testing of the system. In this phase, the instructor needed to remind students on keeping the schedule as there were always revisions and delays in terms of acquiring the parts and fabricating the chamber. The assembly of the chamber was done by March so the students started testing the chamber and its performance in April. Once testing starts, the students found out that one process could affect the performance of the other processes. As a result, they made changes to the chamber and the parameters of the process. For example, once testing started the students found out that they needed a flap valve to control the flow rate of air, and that the air was not heated uniformly with a single heater. The completed chamber was shown in Fig. 2.

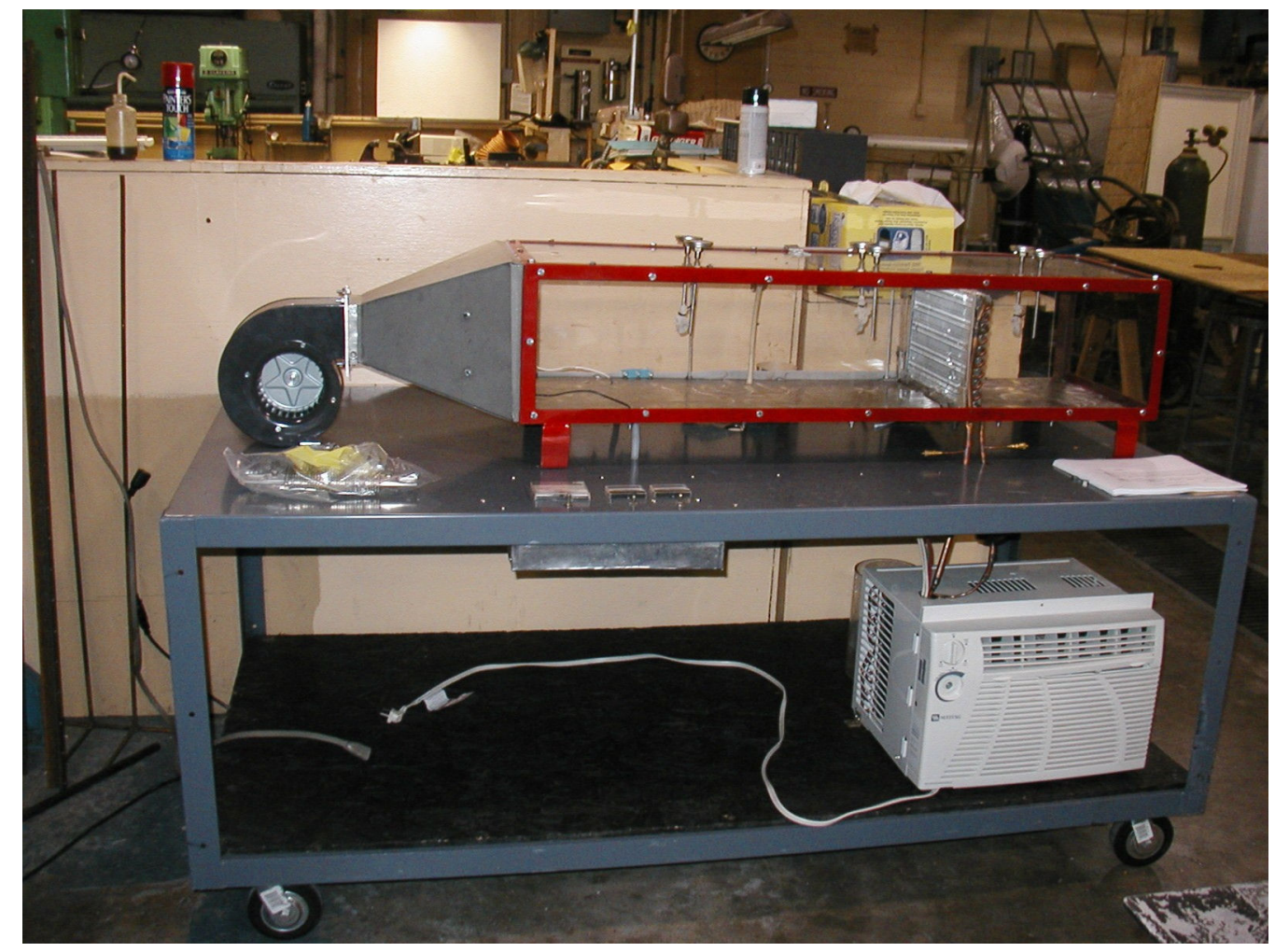

Figure 2 The ASHRAE Chamber

Some of the lessons learned from this project were as follows:

1. The students require the instructor's guidance in terms of identifying the key factors to start tackling the design project.

2. It is essential to communicate to the students from the very beginning the importance of preparing a project time line and meeting the schedule. 
3. The instructor should initiate the research phase of the project (provide literature, point out resources) for the students so that the students can generate engineering specifications following the recommended practices and standards.

4. Even though the students were technical capable, they may fail to consider other aspects of design such as safety, portability, aesthetic, environment, etc.

5. It is importance to stress that successful design is the result of teamwork, and that each team member must contribute to the project. Here, peer review plays a critical role in evaluating the performance of individual member as well as the team.

Paper Snowboard Competition (2004 Energy Challenge)

This project is about a team competed in 2004 Energy Challenge ${ }^{5}$. Energy Challenge competition was formed to teach collegiate level students about recycle/reuse issues as well as waste reduction directly relating to the pulp and paper industry sponsored by the Department of Energy and the Institute of Paper Science and Technology (IPST). Energy Challenge 2004 is a paper snowboard design competition, in which paper is used to construct $80 \%$ of the total weight of the board. Two boards are to be constructed, one of which is to undergo several destructive testing methods at the laboratories at IPST. The second board that is made will be submitted to actual snowboard testing on the slopes of Winter Park, Colorado at the end of the competition.

The students started work right away from the beginning of the semester as the team had to prepare a proposal in early September 2003 to be submitted to IPST. Lamar team was chosen as one of the twelve teams to be funded by DOE and IPST for the project. The initial fund was $\$ 2,000$ to be used in acquiring materials and manufacturing the snowboard. One advantage of being in the design competition is that the students have a specific time line to work on set by IPST, and they must meet the schedule in order to participate in the competition. Some of the requirements of the project are the contents of paper in the final design, collaboration and support from the paper industry and the competition. Since paper industry is more related to chemical than mechanical engineering, students made contacts with the chemical engineering alumni from Lamar University to identify the industrial support. Two companies provided the technical and material support for the project: Temple Inland in Hope, Arkansas provided the resin and technical expertise, and Mead Westvaco provided the raw materials for the snow board. It was a good learning experience for students, as they personally needed to make contact and handle the industrial support phase of the project.

The project required making of two identical snowboards, and deliver them to IPST in March 2004. Typically, the students have until the end of April to complete and test their design but not for this competition. So, they worked through the Christmas break in order to meet the deadline. Based on their research on making snowboard, the students decided to build their own mechanical press [see Fig. 3] and used it to make the snowboard. Next, the construction details of the snowboard and the type of snowboard must be chosen. The freestyle snowboard was chosen, as it was the one most familiar to the team member with snowboarding experience. 


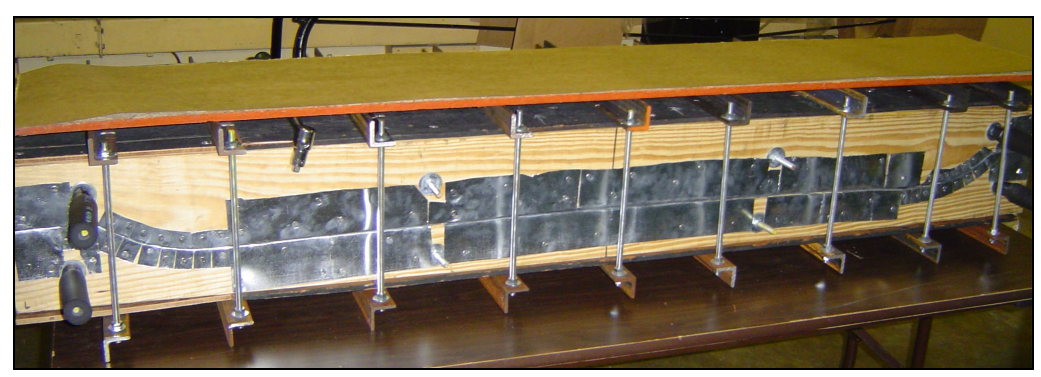

Figure 3 Photograph of the Mechanical Press

In order to produce the template of the snowboard and proper curvature, the team used the SnowCad software ${ }^{6}$. The programs, Pro/ENGINEER and Pro/MECHANICA, were used to develop a three-dimensional model of the snowboard and perform finite element analyses for multiple load scenarios. Once the type and shape of the snowboard was decided, the students turned to making the snowboard. Snowboards are made with multiple layers of different materials. As a result, it is important to identify the materials before making the snowboard. In addition, the rules and regulations of the competition prohibit certain materials (for example, plastic sheets) in the snowboard. Thus, the students conducted a thorough research before deciding on the suitable materials and layout for the snowboard. Figure 4 shows the schematic and the material composition of the snowboard.

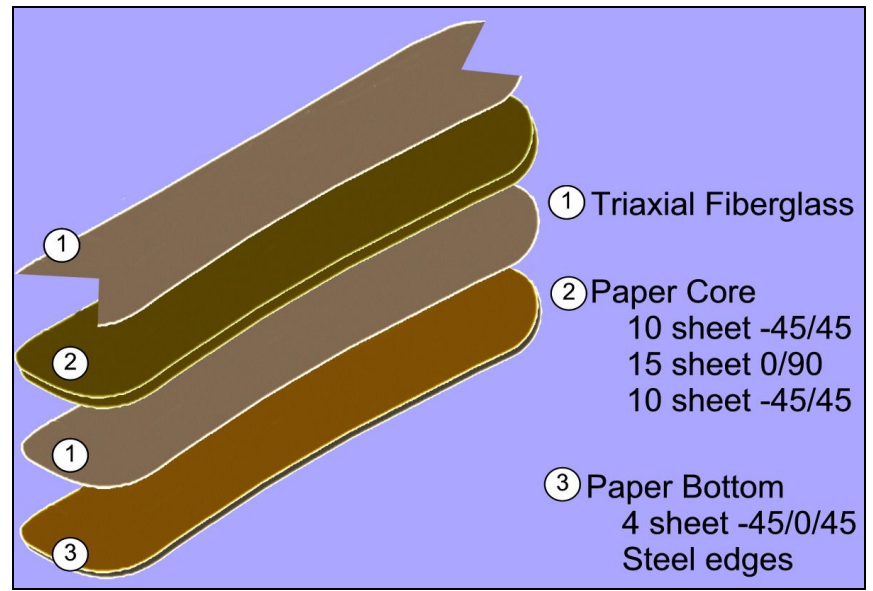

Figure 4 Schematic of snowboard layers and material composition

The next step is to decide on how to bond the different layers so that the final snowboard will withstand water without sacrificing the strength and flexibility required for competition. After trying out several combinations of paper and resin, the students eventually decided on the proper combination of paper and resin. In this phase, the technical expertise and suggestions help from industrial people was very helpful. The students then made a small snowboard for testing its material properties such as hardness and compressive strength. Mechanical Engineering Department has the Materials Laboratory so the students could use testing machines in the laboratory to determine the materials properties of their test board. Once it was done, the two identical snowboards were made and shipped to IPST before the competition in April. In early April, the team went to Denver and participated in the competition. Figure 4 shows the 
completed snowboard. The team got sixth place among the fourteen teams competed in 2004 Energy Challenge.

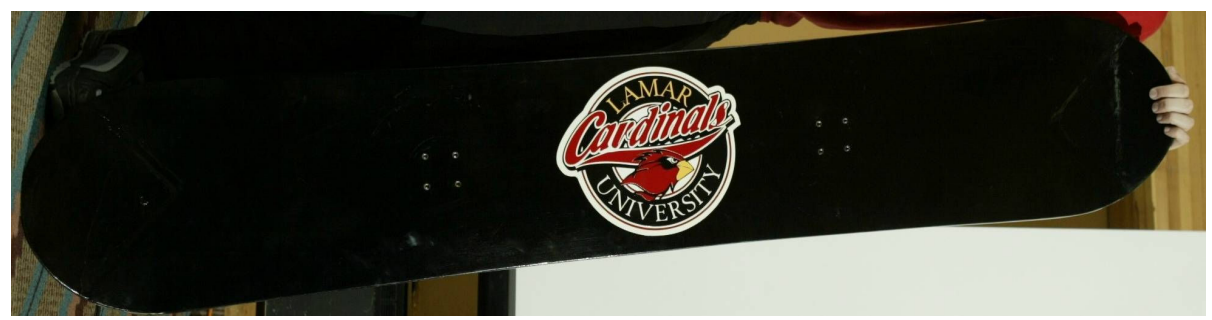

Figure 5 The Photo of the Lamar University Paper Snowboard

Some of the lessons learned from this project were as follows:

1. Projects for design competitions are more stringent in meeting the deadlines and schedules determined by the competition committee. Thus, the students must be carefully guided in every phase of the design so that they will be able to meet the schedule.

2. In design competitions, rules, regulations and requirements must be met. As a result, understanding and clarifying theses issues before developing conceptual designs and identifying the final design is very important.

3. It is important to identify the strengths and weaknesses of each team member early on so that the tasks can be divided and assigned to individual team member. For example, one member of the team was skilled in developing 3-D solid model and finite element analysis so he did most of the work on these areas.

4. The instructor must provide guidance and appropriate resources (research, expertise, finance) for progress of the project and satisfaction of the requirements of the competition.

5. Technical report constitutes a significant part of evaluation of many competitions so the instructor must ensure that the students devote enough time to prepare and complete the report.

6. Technical present also is a significant part of evaluation of many competitions so the instructor must ensure that the students devote enough time to prepare and practice their presentation.

Conclusions

For all engineering students, senior capstone design course is a required course for completion of their bachelor degree. This paper describes the lessons and experiences learned from conducting these capstone design classes in the Department of Mechanical Engineering at Lamar University. The paper presents difficulties and problems encountered in completing these projects from the viewpoints of both instructor and students. Each project and the problems associated with it were discussed in details. The experiences and lessons learned from these projects are applicable to most capstone design projects and thus, the paper will be beneficial to other instructors teaching capstone design classes. 
Bibliography

1. Evensen, H. A., Zenner, P. F., Grimm, T. R., Tervo, M. D., "Developing an Industry Sponsored Capstone Learning Environment," Proceedings of the 2003 ASEE Annual Conference and Exposition, Nashville, Tennessee, 2003.

2. Griffin, P. M., Griffin, S. O., and Llewellyn, D. C., "The Impact of Group Size and Course Length on a Capstone Design Course," Proceedings of the 2003 ASEE Annual Conference and Exposition, Nashville, Tennessee, 2003.

3. Ullman, D. G., 2003, "The Mechanical Design Process," $3^{\text {rd }}$ Edition, McGraw Hill.

4. http://www.ashrae.org/template/AssetDetail/assetid/23637

5. $\quad$ http://www.ipst.gatech.edu/energy challenge/

6. $\quad$ http://www.snowcad.com/

Biography

KENDRICK AUNG is an assistant professor in the Department of Mechanical Engineering at Lamar University. He received his Ph.D. degree in Aerospace Engineering from University of Michigan in 1996. He is an active member of ASEE, ASME, AIAA, SAE and Combustion Institute. He has published over 50 technical papers and presented several papers at national and international conferences. 